\title{
Evaluasi Peracikan Injeksi Seftriakson di Salah Satu Rumah Sakit Swasta di Semarang
}

\author{
Dina C. A. Putri, Sri H. Yuliani \\ Fakultas Farmasi, Universitas Sanata Dharma, Yogyakarta, Indonesia
}

\begin{abstract}
Abstrak
Injeksi seftriakson merupakan antibiotik spektrum luas golongan sefalosporin generasi ketiga, yang dalam penggunaannya di rumah sakit memerlukan proses peracikan, yaitu rekonstitusi dan pengenceran. Sesuai dengan peraturan dan pedoman yang berlaku, peracikan sediaan steril harus dilakukan dengan fasilitas yang sesuai, proses peracikan yang aseptis, dan dilakukan oleh tenaga kefarmasian, sehingga diperoleh sediaan dengan kualitas dan stabilitas yang baik. Penelitian ini bertujuan mengamati proses peracikan dan sifat fisik hasil peracikan sediaan injeksi seftriakson yang dilakukan di salah satu rumah sakit swasta di Semarang dalam periode April-Mei 2017. Penelitian dilakukan secara observasional terhadap personel peracik, fasilitas dan proses peracikan sediaan injeksi seftriakson. Observasi dilakukan dengan bantuan check list yang disesuaikan dengan pedoman pencampuran obat suntik dan penanganan sitostatika. Sebanyak 60 proses peracikan injeksi seftriakson digunakan sebagai sampel. Hasil peracikan dengan kondisi proses paling tidak sesuai dengan pedoman diuji kualitas fisiknya meliputi $\mathrm{pH}$, kejernihan dan sterilitas. Hasil penelitian menunjukkan bahwa peracikan sediaan injeksi seftriakson di rumah sakit tersebut belum memenuhi kriteria sesuai pedoman pencampuran obat suntik, terutama dari segi fasilitas dan personel peracik. Meskipun demikian, hasil uji kualitas yang dilakukan terhadap sediaan tersebut masih memenuhi kriteria bebas kuman, isohidris, dan jernih.
\end{abstract}

Kata kunci: Injeksi, peracikan, seftriakson, steril

\section{Evaluation of Ceftriaxone Injection Compounding in One of Private Hospital in Semarang}

\begin{abstract}
Ceftriaxone injection is a broad-spectrum antibiotic of third-generation cephalosporin. Its use in hospitals requires reconstitution and dilution to obtain the desired dose. Compounding of sterile preparations is supposed to be carried out with appropriate facilities, aseptic compounding process, and performed by a pharmacist, in accordance with regulations and guidelines, to obtain a good quality and stability of ceftriaxone injection. The aim of this study was to evaluate the compounding process of ceftriaxone injection preparation in one of a private hospital in Semarang at April-May 2017.The study was done by observing the compounding of ceftriaxone injection preparations involving the facility, process, and personnel. Observations were conducted using the checklist from Sterile Dispensing Guidelines. Sixty compounding of ceftriaxone injection were used as samples. Observation results were used to determine the process of compounding with the worst possible condition, and then $\mathrm{pH}$, clarity, and sterility were tested to evaluate its physical quality. The results showed that compounding of ceftriaxone injection in the hospital do not conform the criteria according to the preparation of injectable guidelines, especially in terms of facilities and personnel. However, the results of quality tests performed still accord the criteria, i.e, free from microbe, isohydris and clear.
\end{abstract}

Keywords: Ceftriaxone, injection, compounding, sterile

Korespondensi: Dina C. A. Putri, M.Sc., Apt., Fakultas Farmasi, Universitas Sanata Dharma, Yogyakarta 55284, Indonesia, email: dinachristinayuningputri@gmail.com

Naskah diterima: 6 Oktober 2017, Diterima untuk diterbitkan: 13 Juli 2018, Diterbitkan: 1 September 2018 


\section{Pendahuluan}

Direktorat Bina Farmasi Komunitas dan Klinik Departemen Kesehatan Republik Indonesia telah mengeluarkan Pedoman Pencampuran Obat Suntik ${ }^{1}$ dan Pedoman Dasar Dispensing Sediaan Steril ${ }^{2}$ pada tahun 2009. Pedoman tersebut memuat berbagai aspek yang harus diperhatikan dalam peracikan sedian steril, di antaranya sumber daya manusia, fasilitas peracikan, teknik peracikan, kompatibilitas, dan stabilitas sediaan racikan steril. ${ }^{1,2}$ Pedoman yang dapat digunakan dalam peracikan sediaan steril di rumah sakit adalah United States Pharmacopeia (USP) chapter 797 yang memuat berbagai persyaratan teknik aseptis, tenaga peracik, level risiko, prosedur pencampuran, penyimpanan, hingga kontrol kualitas..$^{3-5}$

Penelitian oleh Ulfa et al. ${ }^{6}$ menunjukkan bahwa proses peracikan sediaan steril di Intensive Care Unit (ICU) dan Neonatal Intensive Care Unit (NICU) RSUD Dr. Saiful Anwar Malang masih belum sesuai dengan pedoman yang telah ditetapkan. Pedoman pencampuran sediaan steril ini selayaknya diikuti untuk menghasilkan produk racikan yang steril dan berkualitas. ${ }^{7}$ Proses peracikan merupakan salah satu tahap yang berperan dalam meningkatkan risiko kesalahan terapi (medication error) terutama jika dihasilkan produk yang memiliki kualitas yang tidak sesuai. ${ }^{8}$ Sediaan injeksi yang tidak berkualitas menyebabkan kesehatan pasien memburuk atau bahkan meninggal dunia. ${ }^{9}$

Seftriakson merupakan antibiotik golongan sefalosporin generasi ketiga. Frekuensi penggunaan seftriakson di rumah sakit cukup tinggi baik pada orang dewasa maupun anakanak terutama untuk mengatasi penyakit tifus, ${ }^{10}$ infeksi saluran pernafasan, ${ }^{11}$ infeksi saluran kemih, ${ }^{12}$ dan lain-lain. Frekuensi penggunaan yang tinggi menyebabkan peracikan sefriakson yang dilakukan di suatu rumah sakit juga tinggi, sehingga perlu dilakukan penelitian untuk menjamin kualitas seftriakson injeksi yang diracik di rumah sakit. Penelitian ini bertujuan untuk mengevaluasi proses peracikan sediaan injeksi seftriakson yang mengalami rekonstitusi dan atau pengenceran di salah satu rumah sakit swasta di Semarang yang dibandingkan Pedoman pencampuran Obat Suntik dan Sitostatika.

Hasil penelitian ini diharapkan dapat menjadi evaluasi bagi rumah sakit untuk memperbaiki atau meningkatkan berbagai aspek kritis dalam peracikan sediaan steril yang belum sesuai, dan mempertahankan hal-hal yang sudah sesuai dengan pedoman peracikan sediaan steril.

\section{Metode}

Penelitian ini dilakukan secara deskriptif observasional. Observasi dilakukan di salah satu rumah sakit swasta di Semarang (selanjutnya disebut RS "X") dengan nomor izin penelitian 748.1/RSX/LP/DIKLAT/VIII/2017. Observasi dilakukan terhadap peracikan yang dilakukan terkait berbagai aspek peracikan steril, yaitu fasilitas, tenaga peracik, proses peracikan, dan hasil sediaan racikan. Pengambilan sampel dengan teknik purposive sampling selama periode pengamatan yaitu setiap hari Sabtu dan Minggu selama bulan April-Mei 2017. Seluruh sampel yang memenuhi kriteria inklusi digunakan dalam penelitian.

Kriteria inklusi dalam penelitian ini adalah peracikan sediaan injeksi seftriakson, yang meliputi rekonstitusi dan atau pengenceran di RS "X" dalam periode penelitian. Kriteria eksklusi dalam penelitian ini adalah peracikan sediaan injeksi seftriakson yang dilakukan oleh pihak RS "X" namun tidak teramati keseluruhan prosesnya oleh peneliti.

Observasi

Data dikumpulkan dengan mengamati langsung proses preparasi sediaan seftriakson injeksi. Pada penelitian ini, tidak ditentukan jumlah minimal proses peracikan sediaan injeksi seftriakson sebab pengamatan dilakukan 
sesuai dengan kondisi nyata di RS " $X$ " selama periode penelitian, sesuai kebutuhan di rumah sakit tersebut. Proses pengamatan dilakukan dengan bantuan check list yang dibuat berdasarkan Pedoman Dasar Dispensing Sediaan Steril dan Pedoman Pencampuran Obat Suntik dan Sitostatik.

Uji kualitas fisik

Uji kualitas fisik sediaan racikan injeksi seftriakson ini di antaranya meliputi sterilitas, $\mathrm{pH}$, dan kejernihan. Uji sterilitas dilakukan di Balai Kesehatan Semarang dengan cara menginokulasikan sediaan injeksi seftriakson hasil racikan di RS "X" ke dalam medium pertumbuhan universal yaitu nutrien agar, lalu diinkubasi selama 3 hari, selanjutnya diamati apakah terdapat pertumbuhan bakteri. Uji pH dilakukan dengan menggunakan $\mathrm{pH}$ meter. Uji kejernihan dilakukan secara visual untuk mengamati ada atau tidaknya endapan yang terbentuk. Pengamatan ini dilakukan dengan pencahayaan yang cukup pada latar belakang hitam dan putih.

Pengolahan data

Data observasi yang diperoleh selanjutnya diberi skor. Setiap aspek atau poin yang sesuai dengan pedoman pencampuran obat suntik dan penanganan sitostatik dan pedoman dasar dispensing sediaan steril diberi skor 1, sedangkan yang tidak sesuai diberi skor 0 . Hasil disajikan dalam bentuk persentase yang menyatakan kesesuaian praktik pencampuran sediaan steril menggunakan persamaan sebagai berikut:

$\%$ Kesesuaian $=\frac{\text { Jumlah pencampuran dengan kondisi yang sesuai }}{\text { Jumlah seluruh proses peracikan yang diamati }} \times 100 \%$

Persentase tersebut lalu disajikan dalam bentuk diagram lingkaran untuk membandingkan jumlah proses yang sesuai dan yang tidak sesuai dengan pedoman.

\section{Hasil}

Observasi yang dilakukan dalam periode penelitian melibatkan 60 peracikan sediaan injeksi seftriakson. Observasi meliputi fasilitas, tenaga peracik, proses peracikan, dan hasil sediaan racikan

Persyaratan umum

Persyaratan umum pada peracikan sediaan steril yaitu dilakukan sesuai dengan pedoman dispensing sediaan steril yang dibuat oleh Kementerian Kesehatan Republik Indonesia. Penelitian ini membandingkan persyaratan umum yang terdapat pada pedoman tersebut dengan hasil observasi di RS "X". Ringkasan hasil perbandingan ini dapat dilihat pada Tabel 1. Beberapa persyaratan umum masih belum terpenuhi.

\section{Proses peracikan}

Hasil pengamatan proses peracikan sediaan injeksi seftriakson yang mengalami rekonstitusi dan/atau pengenceran dapat dilihat pada Gambar

Tabel 1 Hasil Pengamatan Persyaratan Umum

\begin{tabular}{lll}
\hline \multicolumn{1}{c}{ Parameter } & \multicolumn{1}{c}{ Persyaratan* } & \multicolumn{1}{c}{ Hasil Observasi } \\
\hline Sumber daya manusia & Apoteker dan tenaga teknis kefarmasian & Perawat dan tenaga teknis kefarmasian \\
Ruangan peracikan & $\begin{array}{l}\text { Terdiri dari ruang persiapan, ruang ganti, } \\
\text { ruang antara, dan ruang steril }\end{array}$ & $\begin{array}{l}\text { Tidak ada ruang khusus peracikan steril. } \\
\text { Hanya dilakukan di ruang perawat }\end{array}$ \\
Peralatan & $\begin{array}{l}\text { Pakaian pelindung, sarung tangan, } \\
\text { masker, kacamata pelindung }\end{array}$ & $\begin{array}{l}\text { Masker dan sarung tangan. Tidak } \\
\text { terdapat pakaian dan kacamata pelindung }\end{array}$ \\
Tempat peracikan & Laminar air flow & Tidak terdapat laminar air flow \\
\hline * Persyaratan mengacu pada Pedoman Dasar Dispensing Sediaan Steril dan Pedoman Pencampuran Obat Suntik dan Sitostatik
\end{tabular}


1. Pada diagram tersebut, tampak bahwa teknik aseptis belum diterapkan sepenuhnya dalam peracikan sediaan injeksi seftriakson.

Sediaan racikan

Hasil pengamatan terhadap sediaan injeksi seftriakson yang telah diracik dapat diamati pada Gambar 2. Dosis dan volume pelarut dalam sediaan injeksi seftriakson yang dihasilkan tidak sesuai secara teoretis dengan Handbook of Injectable Drug. ${ }^{13}$ Etiket atau label yang diberikan belum memenuhi kriteria dari Pedoman Pencampuran Obat Suntik dan Sitostatika.

Uji kualitas fisik

Hasil uji kualitas fisik sediaan seftriakson injeksi yang meliputi sterilitas, $\mathrm{pH}$, warna larutan dan kejernihan dapat dilihat pada Tabel 2. Seftriakson injeksi yang dihasilkan memenuhi parameter bebas kuman, warna, dan kejernihan, namun memiliki $\mathrm{pH}$ yang tidak sesuai.

\section{Pembahasan}

Pencampuran sediaan steril memerlukan perhatian khusus, terutama pada perlindungan produk dari kontaminasi mikroorganisme, perlindungan dari petugas dan lingkungan terhadap paparan, stabilitas sediaan serta ketidaktercampuran sediaan. $^{2}$ Sediaan steril yang terkontaminasi dapat menyebabkan angka kejadian kesalahan terapi pada sediaan injeksi cukup tinggi, ${ }^{14}$ terutama untuk sedian steril yang membutuhkan persiapan khusus sebelum digunakan seperti rekonstitusi atau pengenceran. ${ }^{15}$

Peracikan sediaan steril hendaklah dilakukan oleh tenaga kefarmasian, yaitu apoteker dan
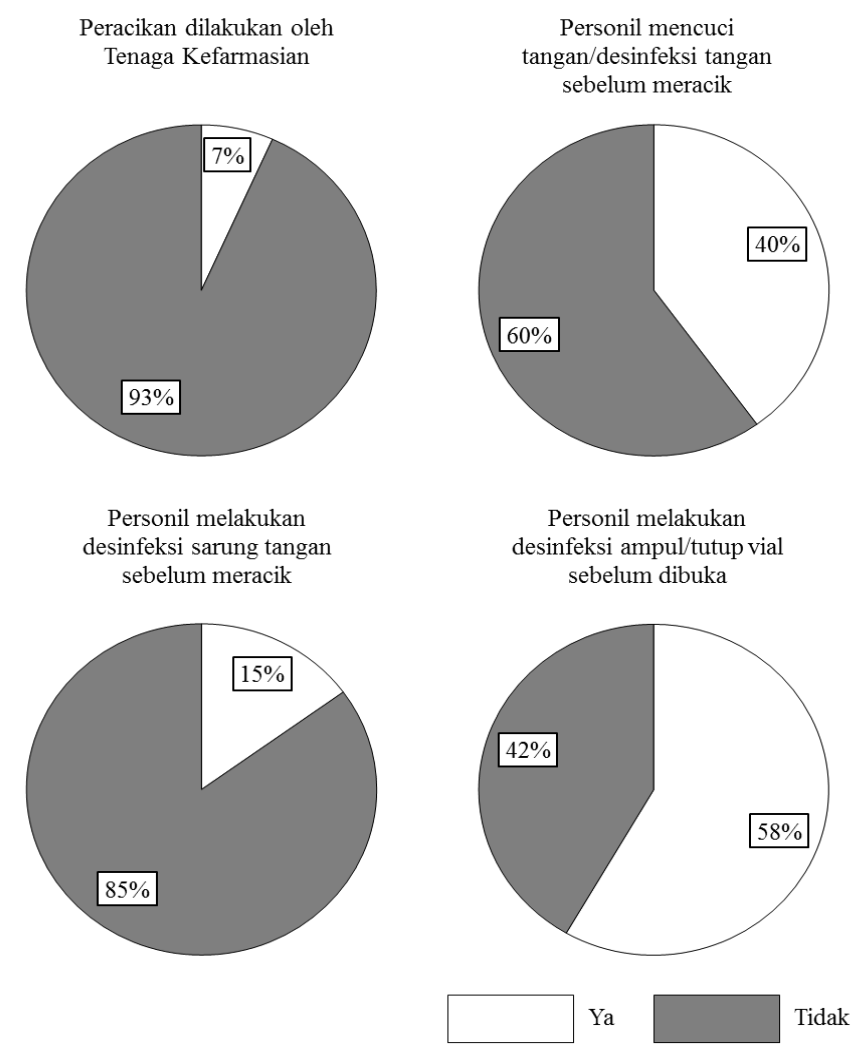
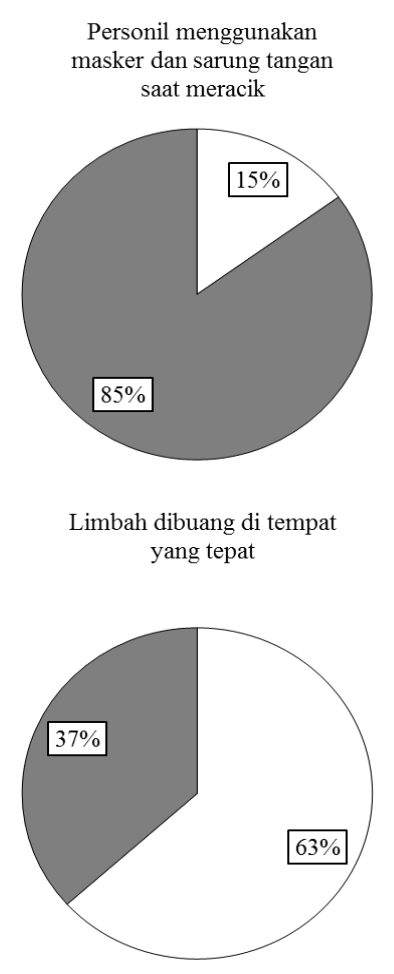

Gambar 1 Hasil Observasi terhadap Proses Peracikan $(n=60)$ 
dibantu oleh tenaga teknis kefarmasian. ${ }^{2} \mathrm{Hal}$ ini sejalan pula dengan Peraturan Menteri Kesehatan Nomor 72 tahun 2016 tentang Standar Pelayanan Kefarmasian di Rumah Sakit, yang menyatakan bahwa peracikan sediaan steril di rumah sakit dilakukan oleh apoteker. ${ }^{16}$ Peracikan injeksi seftriakson di RS " $X$ " masih belum memenuhi kriteria tersebut. Hal ini dibuktikan dengan hasil observasi terhadap 60 proses peracikan injeksi seftriakson (Gambar 1) yang menggambarkan bahwa hanya $7 \%$ injeksi seftriakson diracik oleh tenaga teknis kefarmasian, sedangkan $93 \%$ sisanya dilakukan oleh perawat. ${ }^{17}$
Thomas et al. ${ }^{18}$ melakukan penelitian terhadap proses peracikan yang dilakukan oleh tenaga farmasi dan tenaga nonfarmasi dengan pengalaman kerja selama 5 tahun, melalui validasi proses aseptis atau yang sering disebut dengan media fill. Hasil studi tersebut menunjukkan bahwa peracikan yang dilakukan oleh teknisi atau tenaga kesehatan nonfarmasi menghasilkan sediaan terkontaminasi dengan jumlah yang secara signifikan lebih banyak dibandingkan sediaan yang diracik oleh tenaga kefarmasian. Hal tersebut secara langsung dapat menimbulkan risiko pada kualitas sediaan yang diracik.
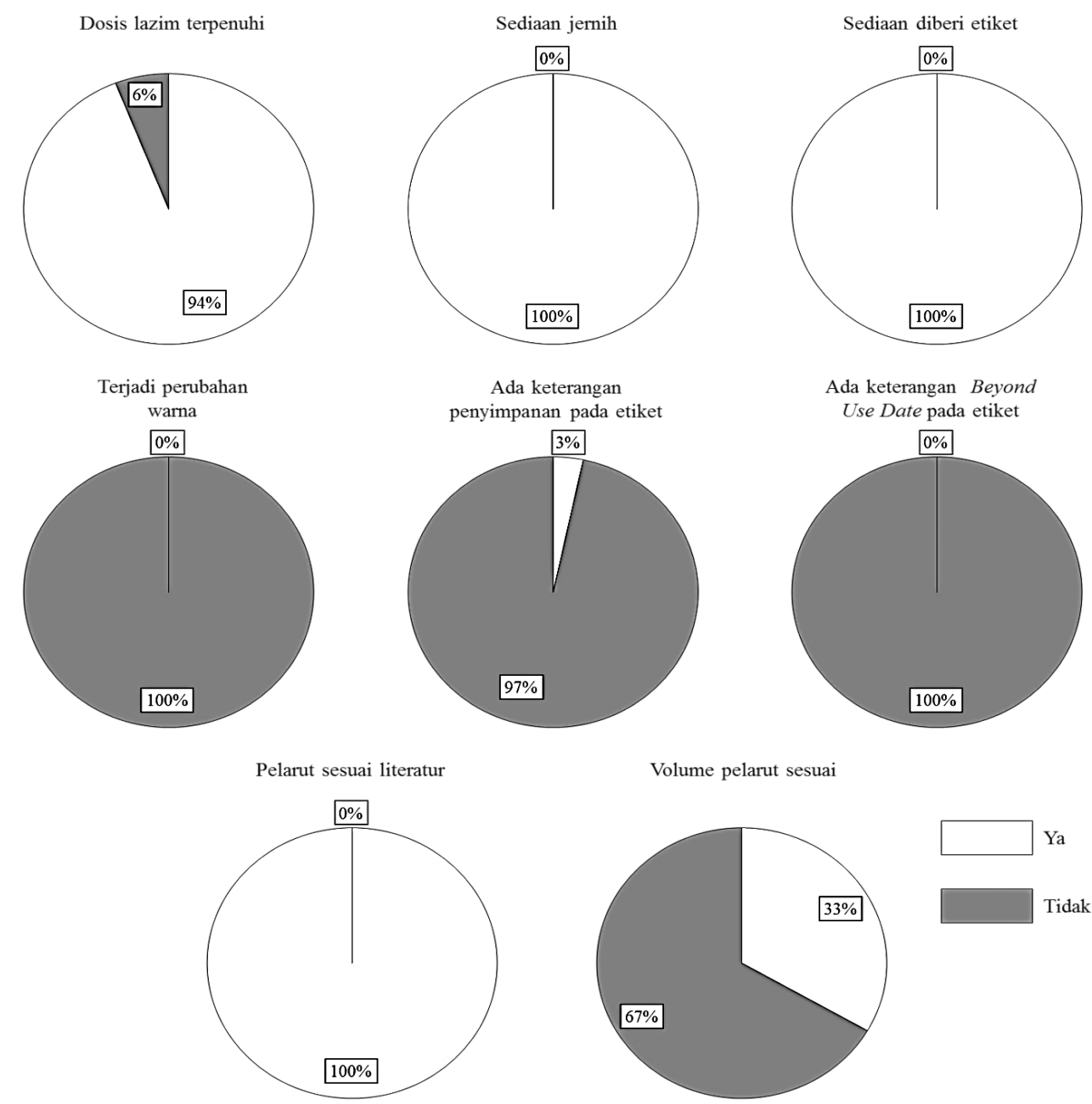

Gambar 2 Hasil Observasi terhadap Hasil Sediaan $(\mathbf{n}=60)$ 
Tabel 2 Hasil Uji Kualitas Fisik Injeksi Seftriakson (n=3)

\begin{tabular}{lll}
\hline \multicolumn{1}{c}{ Parameter } & \multicolumn{1}{c}{ Kualitas Teoritis* } & Hasil \\
\hline Sterilitas & Steril & Bebas kuman \\
$\mathrm{pH}$ & $\pm 6,7(6-8)$ & $6,2 \pm 0,1$ \\
Warna larutan & Kuning muda & Kuning muda \\
Kejernihan & Larutan harus jernih dan bebas partikel & Jernih, bebas partikel \\
\hline *Kualitas teoritis mengacu
\end{tabular}

*Kualitas teoritis mengacu pada Handbook of Injectable Drug ${ }^{13}$

Program pelatihan yang diberikan kepada personel peracik, khususnya perawat pada RS “ $X$ ”, sangat penting untuk dilakukan guna meningkatkan pengetahuan dan keterampilan dalam proses peracikan sediaan steril. ${ }^{19,20}$ Meskipun demikian, penelitian oleh Berdot et al. ${ }^{21}$ menunjukkan bahwa pelatihan belum tentu dapat menurunkan angka kesalahan, akan tetapi setidaknya dapat meningkatkan kesadaran perawat mengenai kemungkinan terjadinya medication error. ${ }^{22}$

Sarana dan prasarana yang terdapat di RS " $\mathrm{X}$ " belum memadai untuk peracikan injeksi seftriakson. Selama observasi berlangsung, peracikan injeksi seftriakson hanya dilakukan di ruang perawat yang tidak dilengkapi dengan sistem tata udara khusus dan kontrol partikel serta mikroba. Laminar Air Flow (LAF) untuk peracikan juga tidak tersedia di RS "X".

Peracikan sediaan steril hendaklah dilakukan di dalam LAF di ruang khusus yang terdiri dari ruang persiapan, ruang ganti, ruang antara, dan ruang steril untuk peracikan, dengan sistem tata udara khusus yang memiliki batas jumlah partikel dan mikroba. ${ }^{2,3,5}$ Apabila peracikan dilakukan di ruangan yang tidak sesuai dengan standar tersebut, maka besar kemungkinan terjadi kontaminasi. Peracikan yang dilakukan di LAF dalam ruang steril atau di ruangan khusus yang sesuai dapat mencegah kontaminasi mikroba pada peracikan sediaan steril secara signifikan dibandingkan sediaan yang diracik di luar kriteria tersebut. ${ }^{23-25}$

Peralatan yang digunakan untuk peracikan injeksi seftriakson di RS "X" menggunakan alat-alat sekali pakai (spuit, jarum suntik, alcohol swab). Alat perlindungan diri (APD) yang tersedia di RS “ $X$ ” untuk peracikan injeksi seftriakson hanya masker dan sarung tangan. Persyaratan APD untuk peracikan sediaan steril adalah pakaian pelindung khusus (yang dapat disterilkan dan tidak berserat), masker, sarung tangan, dan kaca mata pelindung. ${ }^{1,2,5}$ Tujuan utama penggunaan APD adalah untuk melindungi personel peracik dari paparan obat dan melindungi produk terhadap kontaminasi yang berasal dari personel peracik.

Peracikan di RS " $X$ " hendaklah mulai diarahkan menuju proses peracikan oleh tenaga kefarmasian dan dilakukan di LAF di dalam ruang steril supaya dapat menjamin kualitas sediaan yang dihasilkan. Hal ini berhubungan dengan pengetahuan dan keterampilan yang dimiliki oleh tenaga kefarmasian mengenai konsep steril, aseptis, dan upaya pencegahan kontaminasi. Pengetahuan lain tentang dosis obat, stabilitas dan kompatibilitas sediaan racikan steril juga dipahami dengan baik oleh tenaga kefarmasian, sehingga hal tersebut akan mendukung kualitas injeksi seftriakson yang dihasilkan.

Observasi terhadap proses peracikan injeksi seftriakson berpedoman pada Pedoman Pencampuran Obat Suntik dan Sitostatik. Peracikan sediaan steril hendaklah melalui tahap persiapan, pencampuran, pengemasan, dan pelabelan. Peracikan injeksi seftriakson di RS "X" secara umum belum melalui tahap preparasi dengan baik. Obat yang diberikan kepada pasien harus tepat pasien, tepat obat, tepat dosis, tepat waktu, tepat rute, tepat penggunaan, dan tepat dokumentasi. ${ }^{26}$

Perhitungan dosis tidak dilakukan di RS " $\mathrm{X}$ " sehingga berisiko terhadap kesesuaian 
dan ketepatan dosis obat. Preparasi hendaklah terdokumentasi dengan baik guna menjamin mutu dari sediaan yang dihasilkan. ${ }^{1}$ Tahap preparasi yang dilakukan di RS " $X$ " belum melibatkan proses dokumentasi yang baik. Hal ini dapat menjadi evaluasi bagi RS " $X$ " agar meningkatkan prosedur dokumentasi kegiatan.

Peracikan injeksi seftriakson hendaklah dibuat dengan teknik yang aseptis. ${ }^{7}$ Beberapa teknik aseptis yang dapat dilakukan untuk meminimalkan terjadinya kontaminasi dan infeksi nosokomial adalah dengan mencuci kedua tangan sebelum melakukan peracikan, ${ }^{27}$ menggunakan sarung tangan dan masker, ${ }^{28}$ serta melakukan desinfeksi pada tutup vial atau ampul sediaan steril sebelum diracik. ${ }^{29}$

Peracikan dengan teknik aseptis masih belum dijalankan dengan baik pada peracikan injeksi seftriakson, sebagaimana ditunjukkan pada Gambar 1. Selama observasi, sebanyak $40 \%$ personel peracik di RS " $X$ " melakukan tindakan mencuci tangan/desinfeksi tangan sebelum meracik, 15\% menggunakan masker dan sarung tangan saat meracik, dengan $15 \%$ dari jumlah tersebut melakukan desinfeksi pada sarung tangan dan sisanya tidak, serta $58 \%$ melakukan desinfeksi tutup vial atau leher ampul sebelum dibuka.

Hasil dari observasi tersebut menunjukkan bahwa kesadaran terhadap perilaku aseptis pada saat meracik injeksi seftriakson di RS "X" masih kurang. Perilaku atau kebiasaan yang dilakukan pada saat proses peracikan yang tidak tepat dapat meningkatkan risiko kesalahan. ${ }^{14}$ Peracikan injeksi seftriakson yang belum memenuhi persyaratan fasilitas dan proses aseptis dapat menyebabkan peracikan sefriakson tergolong memiliki risiko tinggi terhadap terjadinya kontaminasi. ${ }^{23,30}$

Limbah pada proses peracikan sediaan steril tergolong dalam limbah medis yang harus dibuang di tempat khusus agar tidak mencemari, membahayakan, dan mencegah penyalahgunaan. ${ }^{31}$ Pembuangan limbah-limbah, terutama kemasan obat (vial atau pecahan ampul) dan jarum suntik, harus dibuang di tempat terpisah karena membutuhkan proses pengolahan limbah yang berbeda dengan jenis limbah lain. ${ }^{31,32}$ Sebanyak $63 \%$ personel peracik memiliki kesadaran untuk membuang limbah tersebut di tempat khusus yang sudah disediakan, sedangkan sebanyak 37\% lainnya mencampur limbah tersebut dengan limbah nonmedis.

Sediaan racikan injeksi seftriakson diamati segera setelah diracik dan hasilnya dapat diamati pada Gambar 2. Sebanyak 6\% injeksi seftriakson yang dihasilkan tidak masuk ke dalam rentang dosis lazim (underdose) yang dihitung berdasarkan usia dan berat badan pasien. ${ }^{33}$ Hal ini dapat menimbulkan risiko resistensi antibiotik akibat dosis yang rendah. ${ }^{34}$

Serbuk seftriakson kompatibel dengan air untuk injeksi, larutan glukosa $5 \%$, dan $\mathrm{NaCl}$ $0,9 \%{ }^{1,13}$ Rekonstitusi injeksi seftriakson yang dilakukan di RS "X" menggunakan pelarut yang sesuai dan kompatibel, yaitu air untuk injeksi. Setiap 1 gram seftriakson dilarutkan dengan $10 \mathrm{~mL}$ air untuk injeksi. ${ }^{1,13}$ Sebanyak $67 \%$ seftriakson tidak dilarutkan dengan volume pelarut yang sesuai, yakni sebanyak 3\% ditambahkan sebanyak $20 \mathrm{~mL}$ dan 64\% ditambahkan sebanyak 4-5 mL. Hal ini tentu berpengaruh pada kelarutan obat dan tonisitas sediaan yang dihasilkan. Hasil konfirmasi dengan pihak peracik di RS "X", jumlah volume pelarut menjadi $20 \mathrm{~mL}$ karena ditujukan untuk penggunaan dengan bantuan alat syringe pump (sebagai penambah volume). Tidak terdapat konfirmasi maupun penjelasan lebih lanjut pada saat pengamatan terkait penggunaan pelarut sebanyak $5 \mathrm{~mL}$.

Kualitas sediaan racikan injeksi seftriakson $100 \%$ jernih, tidak mengalami perubahan warna, dan diberikan etiket. Sediaan racikan steril harus diberi etiket dengan informasi yang lengkap dan jelas untuk menurunkan risiko kesalahan dalam terapi. ${ }^{35}$ Etiket pada 
sediaan racikan injeksi seftriakson di RS "X" tersebut masih belum memenuhi ketentuan pada Pedoman Pencampuran Obat Suntik dan Sitostatik. Sebanyak 97\% etiket tidak mencantumkan kondisi penyimpanan yang sesuai, serta $100 \%$ tidak mencantumkan waktu boleh dipakai (Beyond Use Date/BUD) sediaan tersebut.

Kondisi penyimpanan hendaklah dituliskan di dalam etiket agar stabilitas injeksi seftriakson tetap terjaga. BUD dari setiap sediaan berbedabeda tergantung pada pelarut yang digunakan, suhu penyimpanan, dan klasifikasi risiko pencampuran. ${ }^{36}$ BUD penting untuk diketahui dan dituliskan dalam etiket, untuk menjamin produk tersebut digunakan dalam waktu yang tepat. ${ }^{37}$ Sediaan racikan injeksi seftriakson hasil racikan RS " $\mathrm{X}$ " tergolong dalam risiko kontaminasi tinggi sehingga memiliki BUD selama 24 jam setelah diracik pada suhu ruang atau 3 hari pada suhu $2-8{ }^{\circ} \mathrm{C} .{ }^{4,13,38,39}$

Observasi terhadap sarana dan prasarana, proses peracikan, dan hasil sediaan secara keseluruhan belum sesuai dengan pedoman yang dibuat oleh Kementerian Kesehatan Republik Indonesia. Perlu dilakukan suatu pengujian terhadap kualitas injeksi seftriakson yang dibuat di RS "X". Uji kualitas yang dilakukan meliputi sterilitas, kejernihan, dan pH. Pengujian injeksi seftriakson dilakukan 24 jam setelah sediaan tersebut dibuat dan disimpan dalam suhu ruang (sesuai dengan BUD untuk risiko tinggi). Hasil pengujian injeksi seftriakson tersebut kemudian dibandingkan dengan kualitas injeksi seftriakson berdasarkan Handbook of Injectable Drug. Ringkasan hasil uji kualitas dapat diamati pada Gambar 2.

Pengujian $\mathrm{pH}$ pada sediaan perlu dilakukan karena dapat memengaruhi kelarutan dan stabilitas obat. ${ }^{40}$ Kualitas sediaan racikan injeksi seftriakson hasil racikan RS " $\mathrm{X}$ " memiliki kualitas yang sama dengan yang terdapat dari literatur baik dari segi warna, $\mathrm{pH}$, dan kejernihan. Sediaan parenteral harus bebas dari mikroorganime. Hasil pengujian yang dilakukan oleh Laboratorium di Balai Kesehatan menunjukkan bahwa sediaan racikan injeksi seftriakson yang diracik oleh RS " $X$ " dengan fasilitas terbatas dan teknik aseptis yang belum optimal menghasilkan sediaan yang bebas kuman. Hal ini kemungkinan terjadi karena injeksi seftriakson merupakan suatu antibiotik, oleh karena itu kuman yang mengontaminasi akan mati akibat efek bakteriostatik dari obat, atau hal ini dapat pula disebabkan oleh keterampilan personel peracik yang sudah baik.

Implementasi hasil penelitian pada aspek klinis di rumah sakit adalah hasil ini dapat menjadi acuan bagi rumah sakit guna melakukan perbaikan sarana-prasarana. Prosedur standar untuk meracik sediaan seftriakson injeksi juga perlu dibuat serta diimplementasikan sebagai salah satu jaminan mutu dari produk yang dihasilkan. ${ }^{41}$ Kesadaran tindakan atau perilaku aseptis saat meracik perlu ditingkatkan agar kualitas sediaan racikan injeksi seftriakson terjamin serta memperkecil risiko terhadap kualitas sediaan. Apabila sarana-prasarana dan proses peracikan sediaan steril telah dilakukan sesuai dengan pedoman yang ada dan dilakukan validasi, maka sediaan racikan steril seftriakson injeksi yang dihasilkan dapat terjamin kualitasnya, baik dari segi stabilitas fisik sediaan maupun klinis (tepat dosis). Kualitas dari sediaan yang baik tentu akan berpengaruh pula pada kualitas terapi dan mengurangi kemungkinan terjadinya medication error akibat kualitas obat.

\section{Simpulan}

Peracikan sediaan sinjeksi seftriakson di RS "X" Semarang masih belum memenuhi berbagai kriteria yang ditetapkan pada Pedoman Dasar Dispensing Sediaan Steril dan Pedoman Pencampuran Obat Suntik dan Sitostatik. Meskipun demikian, sampel sediaan yang dihasilkan dari proses peracikan di RS tersebut menghasilkan kualitas yang dapat diterima 
dari segi warna, $\mathrm{pH}$, kejernihan, dan bebas kuman. Perbaikan dan peningkatan saranaprasarana dan validasi proses peracikan perlu dilakukan untuk menjamin setiap sediaan injeksi seftriakson yang diracik memenuhi parameter kualitas yang ditetapkan.

\section{Ucapan Terima Kasih}

Penulis mengucapkan terima kasih kepada tim KKN alternatif fakultas farmasi Universitas Sanata Dharma Yogyakarta.

\section{Pendanaan}

Penelitian ini didanai oleh Kementerian Riset, Teknologi dan Pendidikan Tinggi Republik Indonesia dengan nomor kontrak 099/SP2H/ PPM/DRPM/2017.

\section{Konflik Kepentingan}

Seluruh penulis menyatakan tidak terdapat potensi konflik kepentingan dengan penelitian, kepenulisan (authorship), dan atau publikasi artikel ini.

\section{Daftar Pustaka}

1. Ministry of Health of the Republic of Indonesia. Mixing guidelines for injectable drug and cytostatic. Directorate of Community Pharmacy and Clinic of the Ministry of Health of the Republic of Indonesia; 2009.

2. Ministry of Health of the Republic of Indonesia. Basic guidelines for sterile dispensing. Directorate of Community Pharmacy and Clinic of the Ministry of Health of the Republic of Indonesia; 2009.

3. Gudeman J, Jozwiakowski M, Chollet J, Randell M. Potential risks of pharmacy compounding. Drugs R D. 2013;13(1):18. doi: 10.1007/s40268-013-0005-9

4. United States Pharmacopeia Convention.
USP36 NF31, 2013: U. S. Pharmacopeia national formulary. United States: United States Pharmacopeial; 2012.

5. Rich DS, Fricker MP Jr, Cohen MR, Levine SR. Guidelines for the safe preparation of sterile compounds: Results of the ISMP sterile preparation compounding safety summit of October 2011. Hosp Pharm. 2013;48(4):282-94. doi: 10.1310/hpj480 4-282

6. Ulfa FN, Achmad A, Triastuti E. Aseptic dispensing compliance test based on basic guidelines for dispensing sterile provision of the Ministry of Health of the Republic of Indonesia in ICU and NICU RSUD Dr. Saiful Anwar Malang. Pharmaceutical J Indones. 2017;3(1):33-8

7. Surahman E, Mandalas E, Kardinah EI. Evaluation using of sterile preparation by i.v. for infection disease in one of private hospital in Bandung. Pharm Sci Res. 2012; 5(1). doi: 10.7454/psr.v5i1.3416

8. Agyemang REO, While A. Medication errors: Types, causes and impact on nursing practice. Br J Nurs. 2010;19(6):380-5. doi: 10.12968/bjon.2010.19.6.47237

9. Myers CE. History of sterile compounding in U.S. hospitals: Learning from the tragic lessons of the past. Am J Health Syst Pharm. 2013;70(16):1414-27. doi: 10.2146 /ajhp130112

10. Sidabutar S, Satari HI. Choice of empiric therapy of typhoid fever in children: Chloramphenicol or ceftriaxone?. Sari Pediatri. 2016;11(6):434-9. doi: 10.1423 8/sp11.6.2010.434-9

11. Ekawati RN, Subarnas A, Rostinawati T. Evaluation of bacterial sensitivity causes of pneumonia against antibiotics amoxicillin, sefadroksil, trimethoprim, sulfamethoxazole, ceftriaxone and cefecular -based cefotaxime at Regional General Hospital Dr. Slamet Regency of Garut. Farmaka. 2017;15(2):1-10. doi: 10.24198 /jf.v15i2.12338.g5733 
12. Niranjan V, Malini A. Antimicrobial resistance pattern in Escherichia coli causing urinary tract infection among inpatients. Indian J Med Res. 2014;139(6):945-8.

13. Trissel LA. Handbook on injectable drugs. United States: American Society of Health -System Pharmacists; 2011.

14. Westbrook JI, Rob MI, Woods A, Parry D. Errors in the administration of intravenous medications in hospital and the role of correct procedures and nurse experience. BMJ Qual Saf. 2011;20(12):1027-34. doi: 10.1136/bmjqs-2011-000089

15. Grissinger M. Reducing errors with injectable medications. Pharm Ther. 2010; 35(8):428-51.

16. Regulation of the Minister of Health No. 72 Year 2016 about the Standard of Pharmaceutical Care at the Hospital. Ministry of Health of the Republic of Indonesia; 2016.

17. Ding Q, Barker KN, Flynn EA, Westrick S., Chang M, Thomas RE, et al. Incidence of intravenous medication errors in a Chinese hospital. Value Health Reg Issues. 2015;(6):33-9. doi: 10.1016/j.vhri.2015.0 3.004

18. Thomas M, Sanborn MD, Couldry R. I.V. admixture contamination rates: Traditional practice site versus a class 1000 cleanroom. Am J Health Syst Pharm. 2005;62(22):23 86-92. doi: 10.2146/ajhp050078

19. Maharani L, Achmad A, Utami ED. The effect of pharmacist education on the attitudes and knowledge of nurses about parenteral preparations. J Keperawatan Soedirman. 2013;8(2):87-91. doi: 10.208 84/1.jks.2013.8.2.472

20. Bülbül A, Kunt A, Selalmaz M, Sözeri Ş, Uslu S, Nuhoğlu A. Assessment of knowledge of pediatric nurses related with drug administration and preparation. Turk Arc Pediatri. 2014;49(4):333-9. doi: 10.5152/tpa.2014.1751

21. Berdot S, Roudot M, Schramm C, Katsahian
S, Durieux P, Sabatier B. Interventions to reduce nurses' medication administration errors in inpatient settings: A systematic review and meta-analysis. Int J Nurs Stud. 2016;(53):342-50. doi: 10.1016/j.ijnurstu. 2015.08.012

22. Elnour A, Ellahham N, Al Qassas H. Raising the awareness of inpatient nursing staff about medication errors. Pharm World Sci. 2008;(30):182-190. doi: 10.1007/s1 1096-007-9163-6

23. Stucki C, Sautter A-M, Favet J, Bonnabry P. Microbial contamination of syringes during preparation: The direct influence of environmental cleanliness and risk manipulations on end-product quality. Am J Health Syst Pharm. 2009;66(22):20326. doi: 10.2146/ajhp070681

24. Allen JL, Okeke CC. Basics of compounding; Considerations for implementing United States Pharmacopeia chapter 797 pharmaceutical compounding-sterile preparations, part 13. Int J Pharm Compd. 2009;13(3):234-8.

25. Austin PD, Elia M. A systematic review and meta-analysis of the risk of microbial contamination of aseptically prepared doses in different environments. J Pharm Pharm Sci. 2009;12(2):233-42. doi: 10.1 8433/J3JP4B

26. Smeulers M, Verweij L, Maaskant JM, de Boer M, Krediet CP, van Dijkum EJN, et al. Quality indicators for safe medication preparation and administration: A systematic review. PloS One. 2015;10(4):e0122695. doi: 10.1371/ journal.pone.0122695

27. Kampf G, Löffler H, Gastmeier P. Hand hygiene for the prevention of nosocomial infections. Dtsch Ärztebl Int. 2009;106(40):649-55. doi: 10.3238/arzt ebl.2009.0649

28. Sari RY, Suprapti E, Solechan A. Pengaruh Sosialisasi SOP APD dengan Perilaku Perawat dalam Penggunaan APD 
(Handscoon, Masker, Gown) di RSUD Dr. H. Soewondo. Karya Ilmiah S1 Ilmu Keperawatan. 2014;1(6):1-10

29. Hemingway CJ, Malhotra S, Almeida M, Azadian B, Yentis SM. The effect of alcohol swabs and filter straws on reducing contamination of glass ampoules used for neuroaxial injections. Anaesthesia. 2007; 62(3):286-8. doi: 10.1111/j.1365-2044.2 007.04977.x

30. Mullarkey T. Pharmacy compounding of high-risk level products and patient safety. Am J Health Syst Pharm. 2009;66(17 Suppl 5):S4-13. doi: 10.2146/ajhp0108b

31. Amin R, Gul R, Mehrab A. Hospital waste management. Prof Med J. 2013;20(6):988 -94 .

32. Okeke CC, Allen LV. Basics of compounding: Considerations for implementing United States Pharmacopeia chapter 797 pharmaceutical compounding-sterile preparations, part 15: Personnel training, cleansing, and garbing. Int J Pharm Compd. 2009;11(5):420-6.

33. Reference PD. 2017 PDR drug information handbook. PDR Network, LLC; 2016.

34. Utami ER. Antibiotics, resistance, and rationality of therapy. el-Hayah. 2012;1 (4):191-8. doi: 10.18860/elha.v1i4.1783

35. Cohen MR, Smetzer JL. Errors with injectable medications: Unlabeled syringes are surprisingly common; Unintended consequences of high-alert stickers; Easily misread abbreviations. Hosp Pharm. 2008; 43(2):81-84. doi: 10.1310/hp j4302-81

36. Kastango ES, Bradshaw BD. Sterile product compounding: Developing qualitybased standards for pharmacy practice. Infusion. 2003;9(1):23-7.

37. Herawati F. Beyond use date produk steril. Rasional. 2012;10(3):22-4.

38. Allen JL, Okeke CC. Basics of compounding: Considerations for implementing United States Pharmacopeia chapter 797 pharmaceutical compounding-sterile preparations, part 8: Stability and beyonduse dating. Int J Pharm Compd. 2008;12 (4):344-53.

39. Allen JL, Okeke CC. Considerations for implementing United States Pharmacopeia chapter 797 pharmaceutical compoundingsterile preparation, part 3: Risk levels. Int J Pharm Compd. 2007;11(5):404-10.

40. Gorski LA, Hagle ME, Bierman S. Intermittently delivered IV medication and $\mathrm{pH}$ : reevaluating the evidence. J Infus Nurs. 2015;38(1):27-46. doi: 10.1097/N AN.0000000000000081

41. Okeke CC, Allen JL. Basics of compounding: Considerations for implementing United States Pharmacopeia chapter 797 pharmaceutical compounding-sterile preparations, part 16: Suggested standard operating procedures. Int J Pharm Compd. 2009;13(6):546-53. 